\title{
Post-Suicide Grief Work In Family Therapy
}

Fady Hajal, M.D.*

\begin{abstract}
The following case report describes the treatment of a family following the death by suicide of its principle male figure. It describes the way the various family members were helped to deal with the unresolved grief reaction that had come to play a destructive role in the life of this bereaved family. Working with the family group allowed a direct observation of the mourning processes of the various family members. In particular, we could see the attempt of the identified child patient at keeping the memory of the lost object alive become an obstacle to a natural resolution of her mother's mourning at that same loss.
\end{abstract}

Since Freud's original work Mourning and Melancholia (Freud, 1917), increased attention has been focused on the grief and mourning process. Lindemann's (Lindemann, 1944) description of the acute grief reaction and of its deviations from the usual process (abnormal, delayed grief) illuminated some of the connections between aborted and unsuccessful mourning and grief and various psychopathological formations.

Most of the original work on grief, however, was done with adults as the objects of study and inquiry. Children's reactions to losses were indeed puzzling as they did not seem to fit the then identified and described (adult) way of mourning. Children of pre-adolescent age do not seem to go through a mourning process like that described by Freud-consisting of a gradual and painful detachment from the inner representation of the lost object. Barring specific developmental considerations, however, children generally do show a specific and regular pattern in response to the loss of a significant person, summarized by J. Miller:

... reactions include unconscious and sometimes conscious denial of the reality of the parent's death; rigid screening out of all affective responses connected with the parent's death; decrease in self-esteem; feelings of guilt; and persistent unconscious fantasies of an ongoing relationship, or reunion with the dead parent (Miller, 1971, p. 714).

This is quite similar to pathological forms of mourning in the adult. In the survivors of suicide, the normal process of mourning and grief (shock, denial, anger, acceptance, and giving up of the lost object thus allowing development of new relationships and interests) are greatly interfered with. Lindemann and Greer found that:

The survivors of a suicide (someone else's) are likely to get stuck in their grieving and to go on for years in a state of cold isolation, unable to feel close to others and carrying always with them the feelings that they are set apart or under the threat of doom $(1972$, p. 67).

Cain and Fast (1972) talk about the unique impact of parent suicide: 1) its abruptness;

**Dr. Fady Hajal is a Clinical Instructor in Psychiatry, Department of Psychiatry, University of Michigan, Ann Arbor, Michigan 48109. 
2) its lack of inevitability; 3) its implicit accusation and overt rejection of the suicidal's objects; 4) the virtual impossibility of excluding psychic considerations and interpersonal events as causative factors; 5) the unique stresses upon the bereaved following a suicide and the community's tendency to avoid or blame rather than support the suicide survivors.

Given the vicissitudes of the grief process in survivors of suicide and the added risk that an abortive or incomplete resolution may result, it is particularly important to assist these family members in their mourning. This work has an additional preventative dimension as it may prevent the family members from being driven to repeat or otherwise attempt to master the experience in maladaptive ways.

\section{Case Report}

History

Jane was 10 years old when she was brought by her mother for evaluation as a result of a slowly escalating pattern of hostile interaction between them. Jane's development had been essentially normal without any behavior problems reported prior to Mr. A.'s suicide. Now she was constantly grumbling and complaining, testing the limits set by her mother, refusing to carry on her chores around the house. Mrs. A. was disturbed by the lack of communication between them. She blamed it in part on her daughter-who withdraws into her room or her reading, bottling up her feelings, and "who hears you but doesn't listen," and in part on herself, saying, "There isn't enough of me to go around," especially in relation to increased demands, responsibilities, and pressures forced on her since her husband killed himself about a year before the referral took place. Mrs. A. was infuriated by the fact that this behavior was limited to the house as Jane's adjustment at school and in the community was described as excellent.

Mrs. A., in her early thirties, was the youngest of five siblings in a closely knit rural family characterized by strict discipline but warm relationships. Mr. A., in his mid-thirties when he ended his life, was the second youngest of eight children in a family described as wild and including several emotionally disturbed members. He emerged as the one who did well as he graduated from high school and became an auto mechanic. The first year of their marriage was difficult because Mrs. A. was home from school on weekends only and he worked on Saturdays. Mrs. A., who was angered by that state of affairs, thought of divorce, but "there was no time to even talk about it," This period ended as she left school when she became pregnant with Jane. Even though the pregnancy was unplanned, both were happy when Jane was born, particularly $\mathbf{M r}$. A. who had wanted a girl. In addition, Jane was born on his birthday. He grew very fond of her and they remained very close to each other until the suicide.

Mr. A. was described as having always been quiet, becoming particularly uncommunicative when troubled. He frequently had somatic complaints. Although Mrs. A said that they had had a good relationship, she felt she had always given in to him in arguments or discussions as he had stubbornly maintained that he was always correct.

When the second girl was born, four years after Jane, Mr. A. avoided having any sexual contact with his wife for a few months. He repeated this after their third gir! was born two years later. His unexplained avoidance-abstinence lasted about six months, and even after that period their sexual relationship remained very cold. $\mathrm{Mr}$. A.'s behavior was becoming erratic. He bought a motorcycle on which he took long night rides. Then suddenly, and for no apparent reason, he sold it. Once he announced that he had discovered that his father was not really his father; a few days later he came back to say that his two youngest daughters were not his children. He accused his 
wife of having an affair. Mrs. A indignantly denied this. Then, as suddenly, Mr. A. changed his mind, dropped his accusations and apologized to her.

The suicide was a totally unexpected, shattering blow. In attempting to make sense of a seemingly senseless act, the family reconstituted the few days before the suicide and settled on the following story: A few days before he had come back home early, seeming upset by a policeman who had unjustly given him a speeding ticket. He stayed home that day, alone in his room, complaining of stomach pains, uncommunicative as was usual for him in such states. On the day of the suicide, while taking his medication, he said that his stomach pain wasn't going to bother him any more: Was this a subtle message that he had reached a dramatic decision? If it was, it went unnoticed and failed. Later on that afternoon, Mrs. A. heard a gunshot. She rushed upstairs where she found him bleeding from a fatal chest wound.

\section{Therapy Plan}

Jane's desire for privacy, her irritable bossiness and her ostensible press for independence seemed at first to be indications of early adolescence. Upon further examination, these and other qualities signaled Jane's identification with her lost father and an attempt to work through her grief and guilt. In her relationship with her mother and siblings, Jane was clearly playing a parental role. Her struggles with her mother were not "true" attempts to emancipate as much as attempts to achieve a special status in the family, that of an equal and a peer to her mother. Her criticalness of her mother seemed vaguely reminiscent of her father's long-standing stance toward his wife. Jane emphasized repeatedly her alikeness to her father, the similarities in their tastes and interests, almost saying that they could have been the same person, physically and psychologically.

In summary, Jane's behavior and verbal communications were thought to be expressing her identification with her father, one way of holding on to him and keeping him alive. What seemed to be difficulties in the mother/child relationship were in fact residual effects of the cataclysm that occurred in this family in the form of the father's suicide.

To be helpful, therapy had to address itself to the task of promoting and enhancing the grief work. For this pupose, family therapy seemed the approach of choice. This modality provides the grounds for mutual empathic experience as family members are able to observe each other's expressions of grief and share their feelings of loss, guilt, and rage. In addition, the family modality allows direct observation of interactions and style of communication, thus permitting a swifter understanding and confrontation of defensive maneuvers. This technique was originally described by Norman Paul and George H. Grosser as "operational mourning" (Paul and Grosser, 1965).

When drawing up the treatment contract, we agreed to set a termination date. Since family therapy was going to be restricted to working through the grief reaction, it was thought that by the constant refocusing on this issue and by an approach of active anticipation, confrontation and analysis of the defensive maneuvers set up to ward off the various painful affects, it would be possible to achieve that goal in a limited number of sessions-twenty in all. Time limited therapy was deemed to be particularly suited to dealing with this family for it would allow us to work toward a planned, orderly termination. Time becomes an integral aspect of treatment, heightening the therapeutic tension around issues of loss, separation and abandonment (Mann, 1973) Preparing the family for termination from the onset of treatment and allowing them to work through their related feelings in anticipation would be akin to a corrective emotional experience for a family so deeply shaken by the totally unexpected loss of one of its members.
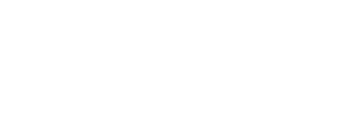
Initial Phase of Therapy: Dealing With the Denial

The first problem encountered was resistance to the undoing of their denialrepression system. Jane did not want to talk about her father's suicide and death: "It's all gone," she said, adding that she doesn't need to talk about it to remember because she always thinks about him. It was as if she had encapsulated his memory and it was hers alone, shared with no one. Wolfenstein (1966) has observed that the internal representation of the lost parent is not decreased in its emotional significance for the child but rather becomes invested with an intensified importance; this was easily observable with Jane. In one of her early attempts to avoid talking about her father, she turned to the play house and set up a family. There, in the middle of the living room, was Father, a very central figure in the family, while one of the girls was up alone in the bedroom. As I confronted her denial with her undoing it in her play, she quickly said that father was going up to his room but she refrained from doing so, and instead, he went to the kitchen to bring the children some goodies and to call the lonely girl down to the family room. This is only one of many examples of her identification with the lost object (the little girl withdrawing into her room), and also her attempt to sustain an image of a giving, caring father against the image of the withdrawing, rejecting father.

Mrs. A.'s resistance to re-opening this chapter of her life was less strong, although she found it easier to talk about current events in her life. But invariably, these events related in some way to the core issue of her husband's absence.

The A. family had a characteristic way of dealing with disturbing happenings. When talking about interpersonal behavior, illness and natural calamities, they insisted: "We are used to it." It was if the suicide, as a sudden, unexpected event, did not exist. That expression was a thin cover-up to many disturbing feelings and a precaution against unexpected pain and disappointment.

The resistances and the defensive system that underlie them appear to have been aimed primarily at preventing each of them from experiencing: 1) the loss, abandonment and feelings of rejection emerging from the very act of the suicide which led to 2 ) a tremendous amount of anger for being rejected, let down, shamed, and narcissis tically injured; and 3) the inevitable guilt feelings that were connected both with the pre-suicide chain of events, self-blame and feelings responsible for the suicide, and on the other hand with the post-suicide anger and rage.

That the defensive system and the resistances play a major role in the maintenance of the status quo is well summarized by J. B. M. Miller (1971, p. 10):

While the primary function of the mourning process is " $t n$ detach the survivors" memories and hopes from the dead" (Freud, 1913) the reactions of object loss in children are seen as having an equally precise and contrary aim, namely to avoid the acceptance of the reality and emotional meaning of the death and maintain in some internal form the relationship that has been ended in external reality.

\section{Identification With and Idealization of the Lost Object}

As both started allowing themselves to re-experience the loss, old feelings re-emerged: first, the shock and disbelief that it had really happened, followed rapidly by the awareness that he "really did it," as Jane put it. Very early during the wake Jane had decided to stop crying; it was her way of saying to herself that he was not really dead, she was not going to let him die. ("If one does not feel bad, nothing bad has happened,"Wolfenstein, 1966, p. 101.) She was going to keep his image very much alive, to the point where she became very much like her father. This identification with the lost object was at times conscious: "I look like my father;" at times unconscious; for example, she always had to be right, and she corrected the slightest mistake that her mother made. This behavior, of onset after the suicide, was clearly directed at her 
mother, in much the way her father had. Mrs. A. fell into the trap, became soft, and ready to give up, as she had done with her husband. When they were confronted with this pattern of interaction, Mrs. A. quickly compared Jane's behavior with that of her husband and was able to identify its hostile quality and express her anger at Jane for doing it.

Jane felt that when her dad died, she had to take over his role by becoming responsible for her two younger sisters. Although she could express how resentful she felt as a result, aiming this anger at the dead father was still strongly prohibited. Rather, her hostility was turned against her mother who was identified as the frustrating, rejecting parent, the rival who had taken father away from her. Jane had felt special and close to her father and these complaints had definite overtones of Oedipal rivalry. It is easy to see how the increasing estrangement between her parents prior to the suicide may have fed into the fantasy that she was very special to him, indeed more special than her mother. Wolfenstein, as quoted by J. Miller (Miller, 1971), has noted in her patients the frequent development of hostile feelings towards the surviving parent, which, together with the idealization of the one who had died, represents an attempt to undo previous hostile feelings towards the dead parent through displacement onto the survivor.

In turn, Mrs. A. appeared irritated by the one-sidedness of Jane's attitude-her bragging about her continued, unfading attachment to her father's memory as if she were accusing her mother of being disloyal to the point where Mrs. A. felt she had to defend herself, saying that she, "too, had had good times with Bob."

In the same vein, Jane kept an idealized image of her father, stressing how good and caring he was, denying any negative behavior on his part. As Mrs. A. would be recalling Mr. A.'s irritability and intransigence, Jane would divert the attention of the group to some detail of Mrs. A.'s clothing and then pick up the discourse, recalling one of the good moments that she had with her father. At one point, she became angry with me as she felt I was devaluing her father's memory by implying that he had had a mental problem. We then looked at some of her needs for preserving such a partial, incomplete memory. They consisted of an attempt to cover up her resentful, angry feelings at the memory of the frustrating, rejecting and humiliating father.

Jane was particularly intolerant of what she called her sister Amy's "dumbness." She felt embarrassed by Amy's "stupid, childish" remarks. She was concerned about what I would think not only of Amy, but also of her. She felt that Amy's poor showing reflected directly upon her. As we looked closer into this feeling, it became clear that Jane thought it was incumbent upon her to take care of her younger siblings to replace her father at mother's side as a responsible grown-up. Amy, with her playfulness, "stupidity," carefreeness, and spontaneity represented the childhood that she, Jane, had had to give up because of the position of responsibility into which she felt thrust by her father's death. As we dealt with this unspoken, unconscious fantasy and the subsequent resentment and clarified her feelings of being robbed of her childhood by having to act in a more mature way (that which she was trying to inflict on Amy), there was a waning of this pattern of relating to her sister.

Amy's spontaneity and carefreeness created difficulties with both Jane and Mrs. A., for Amy, unknowingly, set out destroying the myth of the ideal father. In her own charming way, she was unearthing, from under the thick, defensive formations presented by the two older family members, a number of memories about her father. Although these memories represented him in a more human, down-to-earth fashion, they defied the idealized mental image that Jane and Mrs. A. carried. Amy's recollections that her father had "greasy hair" or that he used to drink brought ferocious attacks and denials. Amy became the target of their hostility because she was "opening the closets with the skeletons inside." They felt betrayed by the child in Amy. We
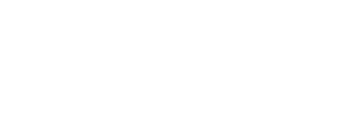
talked about the inappropriate intensity of this denial and refutation and how, in fact, it betrayed a wish to keep an untarnished image and memory of $\mathrm{Mr}$. A., lest they get in touch with their rage.

\section{Facing Guilt and Rage}

When we started our work, it seemed as though the A. family had settled the question of why had he killed himself. Although the explanation left a lot to be desired, they seemed comfortable with it. They did not know why he killed himself? Nothing occurred before to allow them to anticipate it and he never confided his troubles to anyone, so how could they know or do anything about it? A number of friends had told them that they had never suspected that Mr. A. would do such a thing. One already notes the defensive quality of these statements. The only way they made sense of the suicide was to rationalize that it must have been "that cop" who disturbed him so much, or it could have been overwork. Mrs. A. added that "it was good we weren't out on a fun trip, we would have felt guilty then, because he usually refused to go with us on drives." Rather quickly, when pursuing this issue, other concerns emerged. Mrs. A. felt as though people looked at her, staring in an accusatory way. She could say that it was only her imagination, yet she still had to disown these guilty thoughts by project. ing them. She felt that Jane was probably blaming her, too. She explained that since Jane had not been home when the shooting occurred, she may have thought that some argument had developed between her mom and dad, as a result of which, dad killed himself. Mrs. A. thought that this would then explain Jane's hostility towards her. Jane, listening to this, denied in words what her mother was saying, although her facial expression confirmed it. Jane, too, felt that she should have been home. She felt badly that she had been out on a field trip, having fun. Not that she felt guilty about causing the suicide, she carefully explained, but perhaps had she been home, she could have saved her dad. It was as if her mother was bad and unworthy, not only because she may have provoked the suicide, but also because she was unable to save him. Jane's typical stance was to project her guilt feelings on her mother who then became evil. deserving of the blame and punishment which Jane carried out via her identification with her father.

Resisting the move from the old house was another way Jane and her siblings had tried to hold onto the lost past. When Mrs. A., unable to live with the ghost of her husband, had forced the move, Jane had become angry, protesting the fact that she was not consulted in the selection of the new house. This fueled the battle between Jane and mother. Both had felt differently about the house: Jane, idealizing her father, wanted to keep alive all that his hands had touched, whereas Mrs. A., oppressed by the memory and the loss, knew not what more to do to rid herself of it. She described how insurance papers and other letters kept cropping up every time she thought she had gotten over the suicide. She had kept herself busy during the first year by attending to her many new responsibilities. Still, that had not prevented her from feeling the shattering abandonment. She felt that her husband had placed an intolerable burden on her, described his loss as losing part of herself and felt that the other part was unworthy to continue living, adding that if it were not for the children, she would have killed herself. It was clear that her husband's suicide constituted a tremendous narcissistic injury. As Rochlin described:

Loss and damage to selfesteem remain bound throughout life from early childhood onward. Therefore, in the dissolution of a relationship, a satisfying image of the self tends in part to be given up. $(1965$, p. $2-3)$

She described the suicide as a slap in her face, as a blow directed at her. She became aware of the rage she had felt towards her husband leaving her alone to worry about
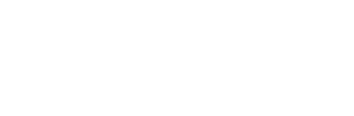
the children: "What would happen to them if I became ill; he could kill himself because he knew I would be around." This guilt-inducing rage (with subsequent retaliatory fantasies) certainly played a major role in the appearance of her fears in the old house: she swore that she heard him walking upstairs, or she felt that the boogy-man was in the house out to get her.

\section{Working Through}

This period of intense confrontation, competition and attempts at mutual control in order to preserve the status quo in the family was followed by a new phase of working through the loss, with the image of the father coming closer to reality. Mrs. A. complained bitterly about being left alone with the children during the holiday season. She recalled how critical of everyone her husband had been and yet how he had been intolerant of any criticism directed at him. We could then look at the sense of inadequacy that he must have possessed which had made him so critical of himself and others and so vulnerable to others' criticisms. Talking about the "critical agency" inside him allowed us to get closer to understanding the kind of motivation which must have led to the suicide. They could feel then that they were no longer to blame themselves.

There was clearly a firming up of the dual image of the lost father and husband. As Jane put it: "He was good at times, and at other times, he was mean and not so good." Things began changing at home. Mrs. A. reported an increasing degree of closeness with Jane to whom she was feeling now more responsive; she was more aware of how each of them felt. She was feeling more at ease in her parenting role, taking firmer stances when needed to discipline the children without feeling as much inadequacy and self-doubt and the consequent resentment and hostility. She became more active and involved in social activities outside the home. She even considered dating again. Earlier she had felt as if her husband's image trailed her, accusing her of being disloyal and bad. It was interesting to observe that the youngest child began moving away from mother's lap during this phase of treatment. Previously she had clung to her, refusing to interact with me or play with her siblings. As Mrs. A. became less depressed and dependent, Susan was able to loosen her tie to her mother.

\section{Termination}

As we moved closer to the contracted termination date, there was a heightening of the feeling of depression in Mrs. A. and an angry withdrawal on Jane's part. Jane hid, stubbornly silent, behind a book of name-finding games. Their feelings were discussed in the context of the upcoming separation. We looked at their progress during the course of treatment as well as the areas that were not touched upon. The experience gained, despite the narrow focus of the therapeutic exploration, was thought to be positive and worthwhile. It had allowed the family members to regain control over a part of their affective lives and behavior that had been frozen in the process of defending against the intolerable feelings of loss, rejection, abandonment, and narcissistic injury, and at their rage and guilt.

But, clearly the grief work for this family is not over. As the two younger siblings grow up, as Jane herself goes through adolescence, they will face and have to cope with new and renewed feelings of loss of their father. It is hoped that this future process will be facilitated by the experience of therapy. In addition, by relatively freeing the parent in this family from the legacy of the suicide and loss, it is expected that she will play a larger and more helpful role with the children in these anticipated tasks.

The ultimate goal of such therapy is preventative. For if one allows the powerful affective experience to remain arrested and repressed, the risk is quite high of

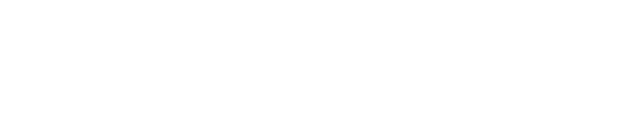


repeating the suicide experience-actively or passively-in an attempt to undo or master it.

\section{REFERENCES}

Cain, A. \& Fast, I. "Children's Disturbed Reactions to Parent Suicide: Distortions of Guilt, Communications, and Identification." In: Survivors of Suicide. Ed., A. Cain. Springfield, Illinois: Charles C. Thomas, 1972, 93-111

Freud, S. "Mourning and Melancholia", 1917, on General Psychological Theory. Ed. P. Rieff. New York: Collier Books, 1963, pp 164-179.

Lindemann, E. "Symptomatology and Management of Acute Grief." American Journal if Psychiatry, 1944, 101, 141-148.

Lindemann, E. \& Greer, I. M. "A Study of Grief: Emotional Responses to Suicide." In. Survivors of Suicide, Ed. A. Cain. Springfield, Illinois: Charles C. Thomas, 1972, 63-69

Mann, J. Time-Limited Psychotherapy. Cambridge, Massachusetts: Harvard University Press. 1973

Miller, J. B. M. Children's Reactions to the Death of a Parent: a review of the psychoanalytic literature. $J$. of the Amer. Psychoanal. Assoc., 1971, 19, 697-719.

Paul, N. \& Grosser, George H. Operational Mourning and its Role in Conjoint Family Therapy Community Mental Health Journal, 1965, 1, 339-345.

Rochlin, G. Grief and Discontents. Boston: Little Brown, 1965.

Wolfenstein, M. How is Mourning Possible? The Psychoanalytic Study of the Child, New York: International Universities Press, 1966, 21, 93-123. 